OPEN ACCESS

Edited by:

Irving E. Vega,

Michigan State University,

United States

Reviewed by:

Maria Cecilia G. Marcondes, San Diego Biomedical Research

Institute, United States

Brian James Morris,

University of Sydney, Australia

*Correspondence:

Huiqin Xing

xinghq@xmu.edu.cn

Specialty section:

This article was submitted to

Neurodegeneration,

a section of the journal

Frontiers in Neuroscience

Received: 25 October 2018

Accepted: 17 January 2019

Published: 04 February 2019

Citation:

Dong $H$, Ye X, Zhong L, Xu J, Qiu J, Wang J, Shao $Y$ and Xing $H$ (2019) Role of FOXO3 Activated by

HIV-1 Tat in HIV-Associated

Neurocognitive Disorder Neuronal Apoptosis. Front. Neurosci. 13:44.

doi: 10.3389/fnins.2019.00044

\section{Role of FOXO3 Activated by HIV-1 Tat in HIV-Associated Neurocognitive Disorder Neuronal Apoptosis}

\author{
Huaqian Dong ${ }^{1}$, Xiang Ye ${ }^{1}$, Li Zhong ${ }^{1}$, Jinhong Xu' ${ }^{1}$, Jinhua Qiu', Jun Wang ${ }^{1}$, \\ Yiming Shao ${ }^{2}$ and Huiqin Xing ${ }^{1 *}$ \\ ${ }^{1}$ Cancer Research Center, Department of Basic Medical Sciences, Fujian Provincial Key Laboratory of Neurodegenerative, \\ Disease and Aging Research, School of Medicine, Xiamen University, Xiamen, China, ${ }^{2}$ State Key Laboratory for Infectious \\ Disease Prevention and Control, Collaborative Innovation Center for Diagnosis and Treatment of Infectious Diseases, \\ National Center for AIDS/STD Control and Prevention, Chinese Center for Disease Control and Prevention, Beijing, China
}

There are numerous types of pathological changes in human immunodeficiency virus (HIV)-associated neurocognitive disorder (HAND), including apoptosis of neurons. HIV-1 transactivator of transcription (Tat) protein, which is encoded by HIV-1, may promote apoptosis in HAND. Forkhead box $\mathrm{O} 3$ (FOXO3) is a multispecific transcription factor that has roles in many biological processes, including cellular apoptosis. The aim of this study was to determine whether $\mathrm{FOXO} 3$ is activated by HIV-1 Tat and to investigate its role in neuronal apoptosis in HAND. We employed tissue staining and related molecular biological experimental methods to confirm our hypothesis. The in vivo experimental results demonstrated that the expression of nuclear FOXO3 increased in the apoptotic neurons of the cerebral cortexes of rhesus macaques infected with simian human immunodeficiency virus (SHIV). The in vitro investigation showed that HIV-1 Tat activated FOXO3, causing it to move from the cytoplasm to the nucleus via the c-Jun N-terminal kinase (JNK) signaling pathway in SH-SY5Y cells. Moreover, FOXO3 down-regulated expression of the anti-apoptosis gene B-cell lymphoma $2(\mathrm{Bcl}-2)$ and up-regulated the expression of the pro-apoptosis gene Bcl-2-like 11 (Bim) after entering the nucleus, eventually causing cellular apoptosis. Finally, reduction of nuclear FOXO3 reversed cellular apoptosis. Our results suggest that HIV-1 Tat induces FOXO3 to translocate from the cytoplasm to the nucleus via the JNK signaling pathway, leading to neuronal apoptosis. Agents targeting $\mathrm{FOXO} 3$ may provide approaches for restoring neuronal function in HAND.

\section{Keywords: FOXO3, apoptosis, HIV-1 Tat, HIV-associated neurocognitive disorder, JNK}

\section{INTRODUCTION}

Impairment of cognition induced by human immunodeficiency virus (HIV) is known as HIVassociated neurocognitive disorder (HAND) and is an important chronic central nervous system syndrome affecting HIV-infected individuals (Antinori et al., 2007). The incidence of HAND among HIV-infected people is 15-50\% (McArthur et al., 2010). Patients with HAND may suffer from cognitive dysfunction, deficits in memory and attention, and impairment of motor skills, and so on (Antinori et al., 2007). 
SHIV $_{\text {SF162P4 }}$ is a chimeric simian human immunodeficiency virus, whose pathogenic features have been described (Polacino et al., 2008). This virus contains main genes from HIV- $1_{\text {SF162 }}$ (R5, macrophage-tropic [MT]/non-syncytium-inducing [NSI]) such as tat, rev, enu, and $v p u$, and spliced with the molecular clone simian immunodeficiency virus $\operatorname{SIV}_{\text {mac239 }}$ (Tan et al., 1999). SHIV SF162P4 $_{\text {can }}$ cause immunological suppression and eventually cause rhesus macaques to develop acquired immune deficiency syndrome (AIDS).

The histopathological features of HAND are closely associated with neuronal injury (Fox et al., 1997), and the apoptosis of neurons has been confirmed to be related to neuronal damage (Adle-Biassette et al., 1995; Petito and Roberts, 1995). However, HIV-1 does not infect neurons directly while the neurons suffer damage (Kaul et al., 2001). HIV-1 transactivator of transcription (Tat) is one of the HIV-1-encoded proteins thought to be involved in neuronal injury caused by neurodegeneration (Cadet and Krasnova, 2007), and it can cause neuronal apoptosis both in vitro and in vivo without HIV-1 directly infecting neurons (New et al., 1997; Maragos et al., 2003). However, the apoptosis mechanism of neurons induced by HIV-1 Tat in HAND remains unknown. It is possible that HIV-1 Tat induces neuronal apoptosis via certain regulatory factors or pathways.

Forkhead box O3 (FOXO3) is a member of the FOXO transcription factor subfamily (Greer and Brunet, 2005). FOXO3 activates transcription of relevant target genes, resulting in cellular apoptosis, cell-cycle arrest, aging and DNA repair (Dijkers et al., 2000; Tran et al., 2002; Calnan and Brunet, 2008; Tia et al., 2018). Moreover, FOXO3 can be activated in HIV-1infected macrophages to promote apoptosis of the macrophages (Cui et al., 2008). However, the involvement (or lack thereof) of FOXO3 in the neuronal apoptosis observed in HAND is still poorly understood.

Our study focused on the relationships among FOXO3, HIV-1 Tat and neuronal apoptosis in HAND. We found that expression of FOXO3 in the neuronal nucleus was elevated in HAND and that this phenomenon was associated with neuronal apoptosis in rhesus macaques infected with SHIV, which were used as HAND animal models. We hypothesized that FOXO3 is activated by HIV-1 Tat and that it participates in neuronal apoptosis in HAND.

\section{MATERIALS AND METHODS}

\section{SHIV-Infected Animals}

Twelve rhesus macaques that were found to be seronegative for SHIV, B virus, SIV, simian T-lymphotropic virus and type D retroviruses were screened. Eight SHIV-infected rhesus macaques (\#1-8) were all intravenously inoculated at the age

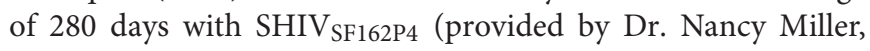
National Institute of Allergy and Infectious Diseases, National Institutes of Health, Bethesda, MD, United States), and the animals were sacrificed 196 days later. Four rhesus macaques not infected with the virus (\#10-13) constituted the control groups (Table 1). The rhesus macaques were kept separately in cages and maintained in rigorous accordance with the rules and guidelines of the National Institute for Infectious Diseases and Experimental Animal Welfare and the Institute of Laboratory Animal Sciences of the Chinese Academy of Medical Science (Xing et al., 2008). The protocol was approved by the Committee on the Ethics of Animal Experiments, Institute of Laboratory Animal Sciences, Chinese Academy of Medical Sciences, China. The rhesus macaques were sacrificed simultaneously after inoculation, when they showed pathological conditions as previously described (Xing et al., 2003, 2009a). On autopsy, viral loads were detected in the peripheral blood of the rhesus macaques using previously published methods (Xing et al., 2003, 2009b) (Table 1).

\section{Hematoxylin and Eosin Staining}

Tissue specimens were obtained from the eight SHIV-infected rhesus macaques and the four control rhesus macaques. After being perfused with $4 \%$ paraformaldehyde, the frontal cerebral cortexes were embedded in paraffin and sliced into $5-\mu \mathrm{m}$ thick sheets. Hematoxylin and eosin (HE) staining was performed using the Hematoxylin and Eosin Staining Kit (Beyotime Biotechnology, C0105) after dewaxing the tissue.

\section{Immunohistochemistry and Double-Labeling}

A streptavidin peroxidase (SP) kit (Maixin Biotechnology, China, KIT-9720) was used for immunohistochemistry (IHC). Antibodies used in the IHC analysis included anti-glial fibrillary acidic protein (GFAP) antibody (1:200, Millipore, AB5541), anti-FOXO3 antibody (1:100, Abcam, ab53287), neuron specific nuclear protein (NeuN) antibody (1:200, Abcam, ab104224), cleaved caspase-3 antibody (1:200, Cell Signaling Technology, \#9661). All of the experimental procedures were performed strictly in accordance with the manufacturers' instructions.

To confirm the location of FOXO3 in rhesus macaque cerebral cortex neurons, double-labeling IHC was performed using the EnVision method. The EnVision method is also called ELPS (enhanced labeled polymer system) method. After the antigen-antibody reaction is combined, the second antibody is labeled with a multimeric compound (glucan) enzyme complex (EnVision complex), and is bound to the first antibody. Further, color development is performed by an enzyme substrate. The EnVision complex utilizes a multimeric compound to simultaneously label HRP or AKP and a secondary antibody (anti-mouse or anti-rabbit $\operatorname{IgG}$ ) on a multimeric compound, that is to say, an enzyme-polymeric compound-second antibody macrocomplex. The secondary antibodies which we used included Simple Stain ${ }^{\mathrm{TM}}$ MAX PO (R) (Nichirei, 424141) and Simple Stain ${ }^{\text {TM }}$ MAX AP (M) (Nichirei, 414241). FOXO3 (1:100) was labeled with 3,3'-diaminobenzidine (DAB)/peroxidase (PO) (Maixin Biotechnology, DAB0031), and then NeuN (1:200) was labeled with PermaBlue Plus/alkaline phosphatase (AP) (Diagnostic Biosystems, K058).

To confirm neuronal apoptosis in the rhesus macaques cerebral cortex and to investigate the relationship between neuronal apoptosis and the location of $\mathrm{FOXO} 3$ in the nucleus, we again used double-labeling IHC. Cleaved caspase-3 (1:200) was 
TABLE 1 | Information about rhesus macaques used in this research.

\begin{tabular}{|c|c|c|c|c|c|c|c|c|}
\hline Animal no. & Sex & $\begin{array}{l}\text { Age at virus } \\
\text { inoculation } \\
\text { (days) }\end{array}$ & $\begin{array}{l}\text { Duration of } \\
\text { infection } \\
\text { (days) }\end{array}$ & $\begin{array}{l}\text { Age at death } \\
\text { (days) }\end{array}$ & $\begin{array}{c}\text { Viral } \\
\text { inoculums }\end{array}$ & $\begin{array}{l}\text { Viral RNA load in } \\
\text { plasma at autopsy } \\
\text { (copies/mL) }\end{array}$ & $\begin{array}{c}\text { Clinical } \\
\text { information }\end{array}$ & $\begin{array}{c}\text { GFAP-positive } \\
\text { cells* }\end{array}$ \\
\hline 1 & Female & 280 & 196 & 476 & $\mathrm{SHIV}_{S F 162 P 4}$ & 7930000 & $\begin{array}{l}\text { Morbid and } \\
\text { weight loss }\end{array}$ & 2 \\
\hline 2 & Male & 280 & 196 & 476 & $\mathrm{SHIV}_{S F 162 P 4}$ & 1000000 & $\begin{array}{l}\text { Morbid and } \\
\text { weight loss }\end{array}$ & 2 \\
\hline 3 & Female & 280 & 196 & 476 & $\mathrm{SHIV}_{S F 162 P 4}$ & 1660000 & $\begin{array}{l}\text { Morbid and } \\
\text { weight loss }\end{array}$ & 3 \\
\hline 4 & Male & 280 & 196 & 476 & SHIV $_{S F 162 P 4}$ & 2290000 & $\begin{array}{l}\text { Morbid and } \\
\text { weight loss }\end{array}$ & 3 \\
\hline 5 & Female & 280 & 196 & 476 & $\mathrm{SHIV}_{S F 162 P 4}$ & 1340000 & $\begin{array}{l}\text { Morbid and } \\
\text { weight loss }\end{array}$ & 2 \\
\hline 6 & Male & 280 & 196 & 476 & $\mathrm{SHIV}_{S F 162 P 4}$ & 2050000 & $\begin{array}{l}\text { Morbid and } \\
\text { weight loss }\end{array}$ & 3 \\
\hline 7 & Female & 280 & 196 & 476 & $\mathrm{SHIV}_{S F 162 P 4}$ & 4970000 & $\begin{array}{l}\text { Morbid and } \\
\text { weight loss }\end{array}$ & 2 \\
\hline 8 & Male & 280 & 196 & 476 & $\mathrm{SHIV}_{S F 162 P 4}$ & 9650000 & $\begin{array}{l}\text { Morbid and } \\
\text { weight loss }\end{array}$ & 3 \\
\hline 10 & Female & / & / & 1092 & Control & 0 & / & / \\
\hline 11 & Male & / & / & 2562 & Control & 0 & / & / \\
\hline 12 & Male & / & / & 1463 & Control & 0 & / & / \\
\hline 13 & Male & / & / & 1771 & Control & 0 & / & / \\
\hline
\end{tabular}

*Immunohistochemical staining for GFAP antigen was assessed semi-quantitatively by scoring from 0 to 3 in each animal.

labeled with DAB/PO, and then NeuN (1:200) or FOXO3 (1:100, Proteintech, 66428-1-Ig) was labeled with PermaBlue Plus/AP.

\section{Cell Culture and Transfection}

SH-SY5Y cell line was purchased from American Type Culture Collection (Manassas, VA, United States). The cells were maintained in basic Dulbecco's modified Eagle's medium (DMEM) (Gibco, C11995500BT) containing 10\% fetal bovine serum (FBS) (Gibco, 12657-029), $100 \mathrm{mg} / \mathrm{mL}$ streptomycin and $100 \mathrm{U} / \mathrm{mL}$ penicillin at $37^{\circ} \mathrm{C}$ in a humidified incubator with $5 \%$ $\mathrm{CO}_{2}$.

Plasmids of pcDNA3.1-tat-flag and pcDNA3.1-flag were prepared in the E. coli $\mathrm{DH} 5 \alpha$ strain and extracted by using Endofree Maxi Plasmid Kit (TIANGEN, DP117). Specific smallinterfering RNA (siRNA) for FOXO3 and a scrambled negative control were purchased from Ruibo Company (Guangzhou, China). The plasmids and siRNA were transfected in the presence of reduced serum medium (Opti-MEM) (Gibco, 1440030) with Lipofectamine ${ }^{\circledR} 2000$ Transfection Reagent (Invitrogen, 11668019) in accordance with the manufacturer's instructions.

\section{RNA Isolation and Quantitative Real-Time Polymerase Chain Reaction}

RNA was isolated and purified from the cultured SH-SY5Y cells using TRIzol Reagent (Life Technologies, 15596018) according to the manufacturer's instructions. Complementary DNA (cDNA) was generated by reverse transcription with the ReverTra Ace quantitative real-time polymerase chain reaction (qRT-PCR) Master Mix (Toyobo, FSQ-201), and then mix them with specific primers and FastStart Universal SYBR Green Master (ROX) (Toyobo, 11750800). qRT-PCR was performed with the AB7100
RT-PCR system (Applied Biosystems, United States). The amplification included the following process: initial incubation at $95^{\circ} \mathrm{C}^{\circ} \mathrm{C}$ for $10 \mathrm{~min}, 40$ amplification cycles $\left(15 \mathrm{~s}\right.$ at $95^{\circ} \mathrm{C}, 1 \mathrm{~min}$ at $60^{\circ} \mathrm{C}$ ), and a final melting curve from 60 to $95^{\circ} \mathrm{C}$. Information regarding primers for various specific genes is presented in Table 2.

\section{Western Blotting Analysis}

Whole-cell lysates of SH-SY5Y cells were obtained using radio immunoprecipitation assay (RIPA) lysis buffer (Boster Biological Technology, AR0105-100) containing protease inhibitor (Roche, 04693132001) and phosphatase inhibitor (Roche, 04906845001). Nuclear and cytoplasmic proteins of SH-SY5Y cells were, respectively, obtained by using the NE-PER ${ }^{\circledR}$ Nuclear and Cytoplasmic Extraction Reagents (Thermo Scientific, \#78833). The concentration of protein was measured using a bicinchoninic acid assay (BCA) Protein Assay Kit (Thermo Scientific Pierce, 23228). Cell lysates (20 $\mu \mathrm{g})$ were loaded and separated with

TABLE 2 | Primers for the qRT-PCR Assay.

\begin{tabular}{lll}
\hline Name & Forward primer $\left(\mathbf{5}^{\prime} \mathbf{-} \mathbf{3}^{\prime}\right)$ & Reverse primer $\mathbf{( \mathbf { 5 } ^ { \prime } \mathbf { - } \mathbf { 3 } ^ { \prime } \mathbf { ) }}$ \\
\hline FOXO3 & CGGACAAACGGCTCACTCT & GGACCCGCATGAATCGACTAT \\
BCl-2 & GGTGGGGTCATGTGTGTGG & CGGTTCAGGTACTCAGTCATCC \\
MCL1 & GTGCCTTGTGGCTAAACACT & AGTCCCGTTTGTCCTTACGA \\
P53 & TGTGACTTGCACGTACTCCC & ACCATCGCTATCTGAGCAGC \\
Bim & CAGTGCAATGGCTTCCATGAG & GTATCTCGGCTCCGCAAAGA \\
Trail & CTGAAGCAGATGCAGGACAAGT & TGCTACTCTCTGAGGACCTCTT \\
FasL & CTACCAGCCAGATGCACACA & CCTTGAGTTGGACTTGCCTGT \\
$\beta$-actin & CATGTACGTTGCTATCCAGGC & CTCCTTAATGTCACGCACGAT
\end{tabular}


sodium dodecyl sulfate-polyacrylamide gel electrophoreses (SDSPAGE) (10-15\% polyacrylamide gel) and were transferred onto Immobilon PVDF Transfer Membrane (Sigma, IPVH00010) followed by blocking with $5 \%$ skim milk powder in phosphatebuffered saline (PBS) containing $0.1 \%$ Tween20 (PBS-T) at room temperature for $1 \mathrm{~h}$. Afterward, the membrane were incubated with appropriate primary antibodies, including HIV-1 Tat (1:1000, Abcam, ab63957), GAPDH (1:10000, Abcam, ab181602), FOXO3 (1:1000, Abcam, ab53287), PhosphoFOXO3(S253) (1:1000, Abcam, ab47285), c-Jun (1:1000, Cell Signaling Technology, \#9165), Phospho-c-Jun (1:1000, Abcam, ab4821), AKT (1:1000, Cell Signaling Technology, \#9272), Phospho-Akt (Ser473) (1:2000, Cell Signaling Technology, \#4060), Bim (1:1000, Abcam, ab32158), Mcl-1 (1:1000, Abcam, ab32087), Bcl-2 (1:1000, Abcam, ab32124), Trail (1:1000, Cell Signaling Technology, \#3219) and P53 (1:200, Santa Cruz Biotechnology, sc-126) for one night at $4^{\circ} \mathrm{C}$ atmosphere. The membrane was then incubated with horse-radish peroxidase (HRP)-labeled secondary antibodies (1:3000, Thermo Fisher, 62-6520 and R\&D Systems, HAF008) for $1 \mathrm{~h}$ at room temperature. Signals of the protein bands were detected with Immobilon Western Chemiluminescent HRP Substrate (Millipore, WBKLS0500).

\section{Immunofluorescence}

For immunofluorescence of FOXO3, SH-SY5Y cells were seeded on glass coverslips in 24-well plates and transfected pcDNA3.1tat-flag or pcDNA3.1-flag plasmid for $48 \mathrm{~h}$. The cells were then fixed for $30 \mathrm{~min}$ in $4 \%$ paraformaldehyde solution in PBS at room temperature, permeabilized in $0.5 \%$ Triton $\mathrm{X}$ 100 in PBS for $10 \mathrm{~min}$ and blocked with blocking buffer [5\% bovine serum albumin (BSA)]. Cells were then incubated with anti-FOXO3 antibody (1:50, Abcam) at $4^{\circ} \mathrm{C}$ overnight. Cells were then washed four times with $1 \times$ PBS and incubated on coverslips with fluorescent secondary antibodies (Thermo, \#31506) at room temperature for $1 \mathrm{~h}$. For nuclear staining, the cells were stained with 4',6-diamidino-2-phenylindole (DAPI) (VECTOR, H-1200).

\section{Terminal Deoxynucleotidyl Transferase dUTP Nick End Labeling Assay}

Prior to the experiment, SH-SY5Y cells were seeded in 24-well plates and treated with plasmids for $48 \mathrm{~h}$. The cells were then fixed in freshly prepared $4 \%$ formaldehyde in PBS for $25 \mathrm{~min}$ at $4^{\circ} \mathrm{C}$. After washing the slides with $1 \times$ PBS, cells were permeabilized in $0.2 \%$ Triton $\mathrm{X}-100$ solution in PBS for $5 \mathrm{~min}$. After rinsing the sheets with PBS, cells were stained with the DeadEND ${ }^{\circledR}$ Fluorometric TUNEL System (Promega, G3250) in accordance with the manufacturer's instructions.

\section{Measurement of Caspase 3/7 Activity}

First, the SH-SY5Y cells were inoculated into a 96-well plate and then transfected with plasmid for $48 \mathrm{~h}$. After the cells were processed, the 96-well plate containing cells was removed from the incubator and equilibrated to room temperature. The caspase 3/7 activity was then determined using Caspase-Glo ${ }^{\circledR}$
3/7 Assay Systems (Promega, G8090) according to the operating instructions.

\section{Chemicals}

SP600125 (Abcam, ab120065), diallyl tetrasulfide (DSA4) (Abcam, ab143603), staurosporine (STS) (Cell Signaling Technology, \#9953), and LY294002 (Millipore, \#19-142) were solubilized in dimethyl sulfoxide (DMSO) before use.

\section{Statistical Analysis}

All results were derived from at least three independent repeated experiments. The results were expressed as mean \pm standard deviation. One-way analysis of variance and unpaired-samples $t$-test were used to analyze the data with GraphPad Prism 5.0 statistical software. The level of significance was set at $P<0.05$.

\section{RESULTS}

\section{Viral RNA Loads of the SHIV-Infected Rhesus Macaques}

Eight rhesus macaques (\#1-8) were infected with SHIV, and four (\#10-13) uninfected macaques were used as controls (Table 1). Viral RNA loads in the peripheral blood of the rhesus macaques were analyzed on autopsy. As shown in Table 1, all of the SHIV-infected rhesus macaques showed high viral loads and the uninfected rhesus macaques showed no viral loads.

\section{Pathological Changes in the SHIV-Infected Rhesus Macaque Cerebral Cortex}

HE staining and IHC staining were used to reveal the pathological changes in the cerebral cortexes of SHIV-infected rhesus macaques. Satellitosis and neuronophagia were observed in the cerebral cortexes of the SHIV-infected rhesus macaques (Figures 1A-C). Diffuse astrocytic gliosis and increased accumulation of the intermediate filament GFAP were detected in the cerebral cortexes of SHIV-infected rhesus macaques (Figures 1D,E). There was no correlation between different viral RNA loads in plasma and GFAP-positive cells in the cerebral cortex of SHIV-infected rhesus macaques (Table 1). These results indicated that the pathological manifestations of the SHIV-infected rhesus macaques cerebral cortex was very similar to those in the cerebral cortex of HAND patients (Navia et al., 1986; Masliah et al., 1992; Fan and He, 2016).

\section{FOXO3 Is Increased in the Neuronal Nucleus and It Is Associated With the Neuronal Apoptosis in the SHIV-Infected Rhesus Macaque Cerebral Cortex}

The expression of $\mathrm{FOXO} 3$ in the cellular nuclei of SHIVinfected rhesus macaques cerebral cortexes was higher than that of the control group, as determined by IHC (Figures 2A,B). 


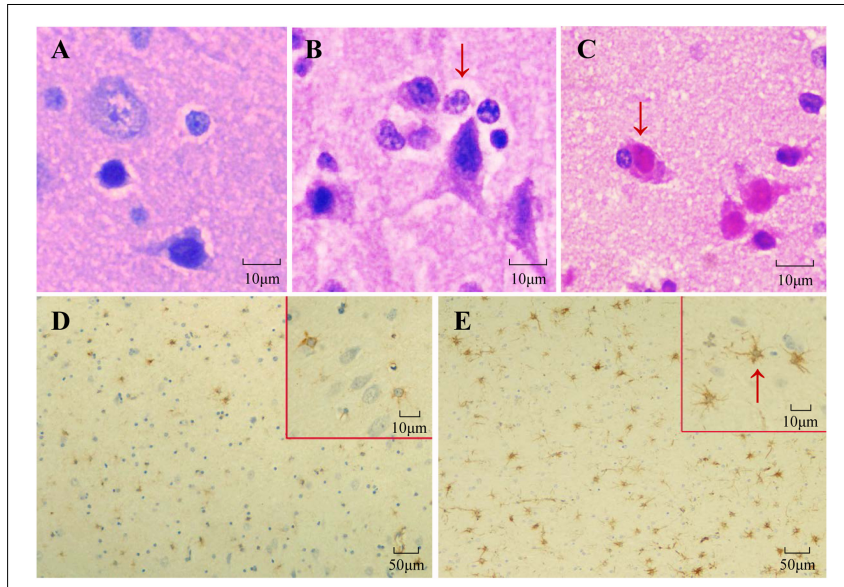

FIGURE 1 | Histopathologic examination of rhesus macaque cerebral cortexes. (A-C) HE staining of rhesus macaque cerebral cortexes. (A) Normal cerebral cortex of the control group. (B) Satellitosis of SHIV-infected rhesus macaques. (C) Neuronophagia of SHIV-infected rhesus macaques. (D,E) The accumulation of GFAP and the quantity of astrocytes were increased in the cerebral cortex of the SHIV-infected rhesus macaques (E) compared with the control group (D), as shown by GFAP (brown) using immunohistochemistry.

In addition, we performed double-labeled IHC for FOXO3 in combination with NeuN. Those results indicated that the FOXO3 neuronal nucleus expression in the cerebral cortexes of the SHIV-infected group was higher than that of the control group (Figures 2C,D). We then utilized double-labeled IHC for cleaved caspase- 3 and NeuN to reveal neuronal apoptosis in the cerebral cortex. There was little neuronal apoptosis in the uninfected rhesus macaque cerebral cortexes, as opposed to more neuronal apoptosis in the SHIV-infected group (Figures 2E,F). Additionally, to further investigate the relationship between increased nuclear expression of FOXO3 and neuronal apoptosis, double-labeled IHC for FOXO3 and cleaved caspase-3 was performed. Neurons were judged based on the shape of cells and the size of the nuclei. There was an increase of FOXO3 in the nuclei of apoptotic neurons (Figures 2G,H). These results revealed that neurons with increased nuclear expression FOXO3 were prone to apoptosis in the SHIV-infected rhesus macaque cerebral cortexes.

\section{HIV-1 Tat Activates FOXO3 to Transfer From Cytoplasm to Nucleus in SH-SY5Y Cells}

To investigate the relationship between HIV-1 Tat and FOXO3 at the cellular level, we chose SH-SY5Y cells and transfected them with plasmids pcDNA3.1-Tat-flag or pcDNA3.1-flag for 48 h. Expression of HIV-1 Tat was measured by Western blotting, HIV-1 Tat was only expressed in cells transfected with pcDNA3.1-Tat-flag (Figure 3A). We then used the two plasmids aforementioned to transfect SH-SY5Y cells separately in order to detect FOXO3 changes in mRNA and protein levels. There was no significant change in FOXO3 at the mRNA level (Figure 3B). However, we found that HIV1 Tat significantly reduced the expression of phosphorylated FOXO3 (Figure 3C). Decreased phosphorylation of FOXO3 is equivalent to increased levels of dephosphorylation of FOXO3, which indicates that it FOXO3 is activated, which causes it to enter the nucleus to play a role in promoting transcription (Brunet et al., 1999). We then extracted the cytoplasmic and nuclear proteins from the SH-SY5Y cells and quantified
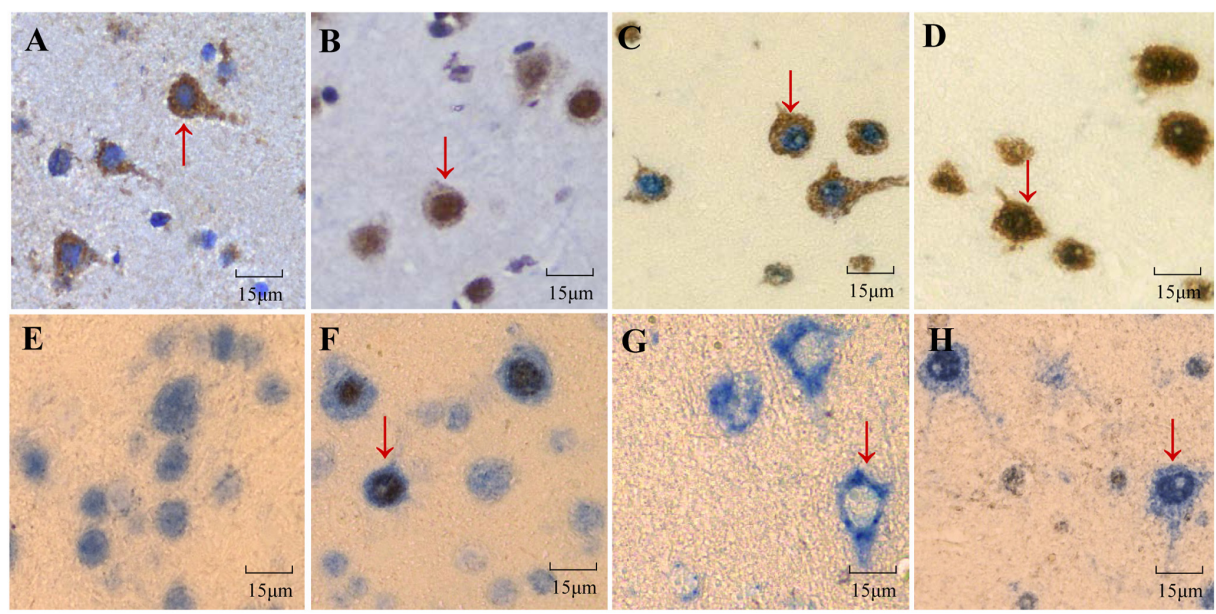

FIGURE 2 | Expression of FOXO3 in rhesus macaque cerebral cortexes and its correlation with neuronal apoptosis. (A,B) Expression of FOXO3 (brown) in the nucle of cells of the cerebral cortexes of SHIV-infected rhesus macaques (B) was higher than that of the control group (A), as analyzed by immunohistochemistry. (C,D) Double-labeled IHC demonstrated that nuclear FOXO3 expression was higher in the nuclei of neurons of the cerebral cortexes of SHIV-infected rhesus macaques (D) than in the control group (C) (FOXO3 was brown, NeuN was blue). (E,F) Neuronal apoptosis in the cerebral cortex of SHIV-infected rhesus macaques (F) was manifested by cleaved caspase-3 (brown) and NeuN (blue) through double-labeled IHC in contrast with little neuronal apoptosis of the control group (E). (G,H) The expression of nuclear FOXO3 in apoptotic cells of SHIV-infected rhesus macaques was higher than that in the control group according to FOXO3 (blue) and cleaved caspase-3 (brown) using double-labeled IHC. 
A

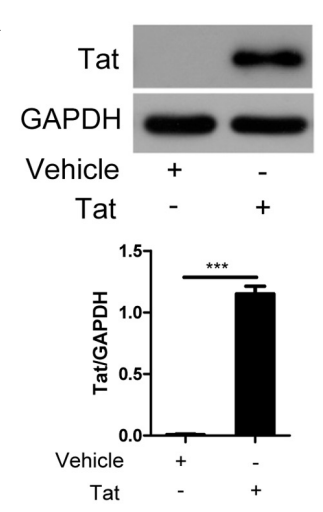

D
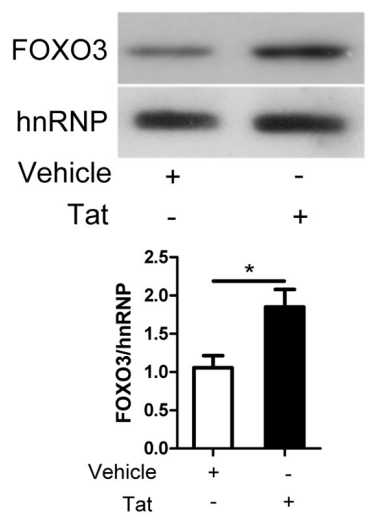

B

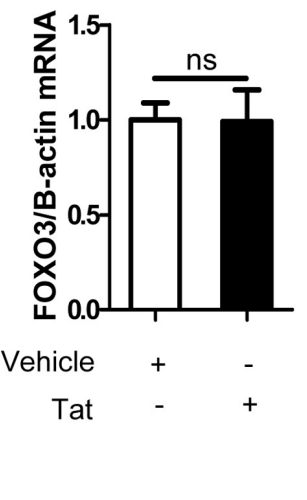

E
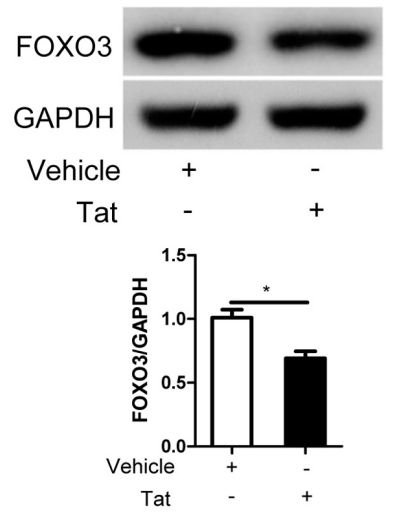

$\mathrm{FOXO} 3$
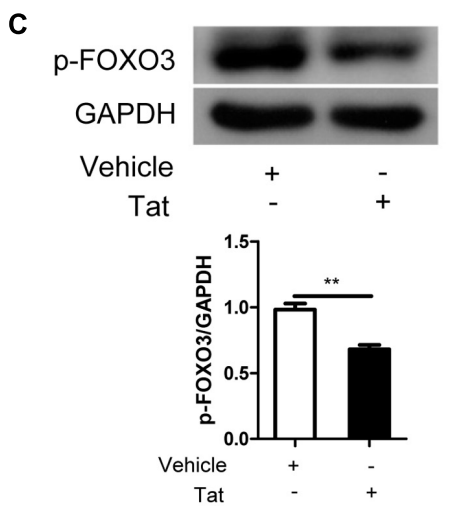

F

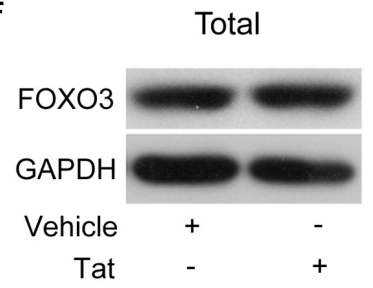

G

DAPI
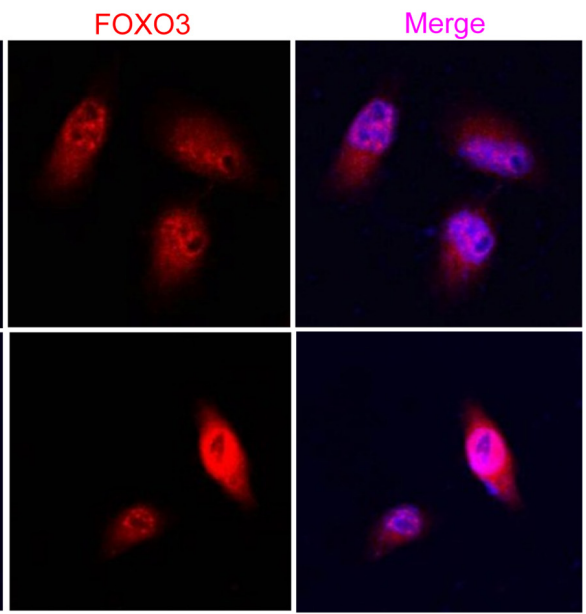

FIGURE 3 | HIV-1 Tat alters FOXO3 intracellular localization in SH-SY5Y cells. SH-SY5Y cells were transfected with pcDNA3.1-flag (4 $\mu$ g) or pcDNA3.1-Tat-flag $(4 \mu \mathrm{g})$ for $48 \mathrm{~h}$. (A) Expression of HIV-1 Tat was measured with Western blotting. Statistical analysis is below $(* * * P<0.001)$ (B) Statistical analysis of the mRNA level of FOXO3 as measured by qRT-PCR. (C) The expression of phosphorylated FOXO3 was analyzed with Western blotting. Statistical analysis is below (**P $<0.01$ ). (D-F) The expression of nuclear FOXO3, cytoplasmic FOXO3 and total FOXO3 was analyzed by Western blotting. Statistical analysis is below $\left({ }^{*} P<0.05\right)$. (G) The nuclear translocation of FOXO3 was observed by confocal microscopy using immunofluorescence staining. Red indicates FOXO3 and blue indicates nuclei. Pictures were magnified $400 x$. Statistical analyses of all Western blots were of at least three independent repeated experiments. Vehicle: pcDNA3.1-flag; Tat: pcDNA3.1-Tat-flag.

FOXO3 expression separately in the cytoplasm and nucleus. At the same time, we detected the protein expression of FOXO3 in SH-SY5Y whole-cell lysate. We found that HIV1 Tat increased the expression of $\mathrm{FOXO} 3$ in the nucleus and decreased the expression of FOXO3 in the cytoplasm, but had no significant effect on the expression of total FOXO3 (Figures 3D-F). Immunofluorescence confirmed the result (Figure 3G). These results indicated that HIV-1 Tat 
activated FOXO3 to translocate into the nuclei of SH-SY5Y cells.

\section{HIV-1 Tat Regulation of FOXO3 Intracellular Localization via JNK Signaling Pathway in SH-SY5Y Cells}

To investigate how HIV-1 Tat regulates FOXO3 intracellular localization, we transfected SH-SY5Y cells with plasmids pcDNA3.1-Tat-flag or pcDNA3.1-flag, or treated SH-SY5Y cells with DSA4 (a specific JNK activator), or treated them with the AKT signaling pathway inhibitor LY294002. We found that HIV-1 Tat had no significant effect on the expression and existential forms of AKT, but the phosphorylation level of FOXO3 was decreased by inhibiting AKT with LY294002
(Figure 4A). HIV-1 Tat was found to induce phosphorylation of JNK but had no effect on total JNK, which was similar to DSA4 (Figure 4B). At the same time, HIV-1 Tat promoted dephosphorylation of FOXO3, as did DSA4. To further validate the role of the JNK signaling pathway in HIV-1 Tat regulating the change in position of FOXO3 within the cell, we utilized plasmids pcDNA3.1-Tat-flag or pcDNA3.1-flag to transfect SH-SY5Y cells, or we treated SH-SY5Y cells with the JNK inhibitor SP600125 followed by transfection with pcDNA3.1Tat-flag. We found that HIV-1 Tat promoted phosphorylation of JNK but had no influence on the total expression of JNK and that it facilitated dephosphorylation of FOXO3 (Figure 4C). This effect of HIV-1 Tat was impaired when JNK was inhibited. These results demonstrated that HIV-1 Tat promoted dephosphorylation of $\mathrm{FOXO} 3$ to migrate it from
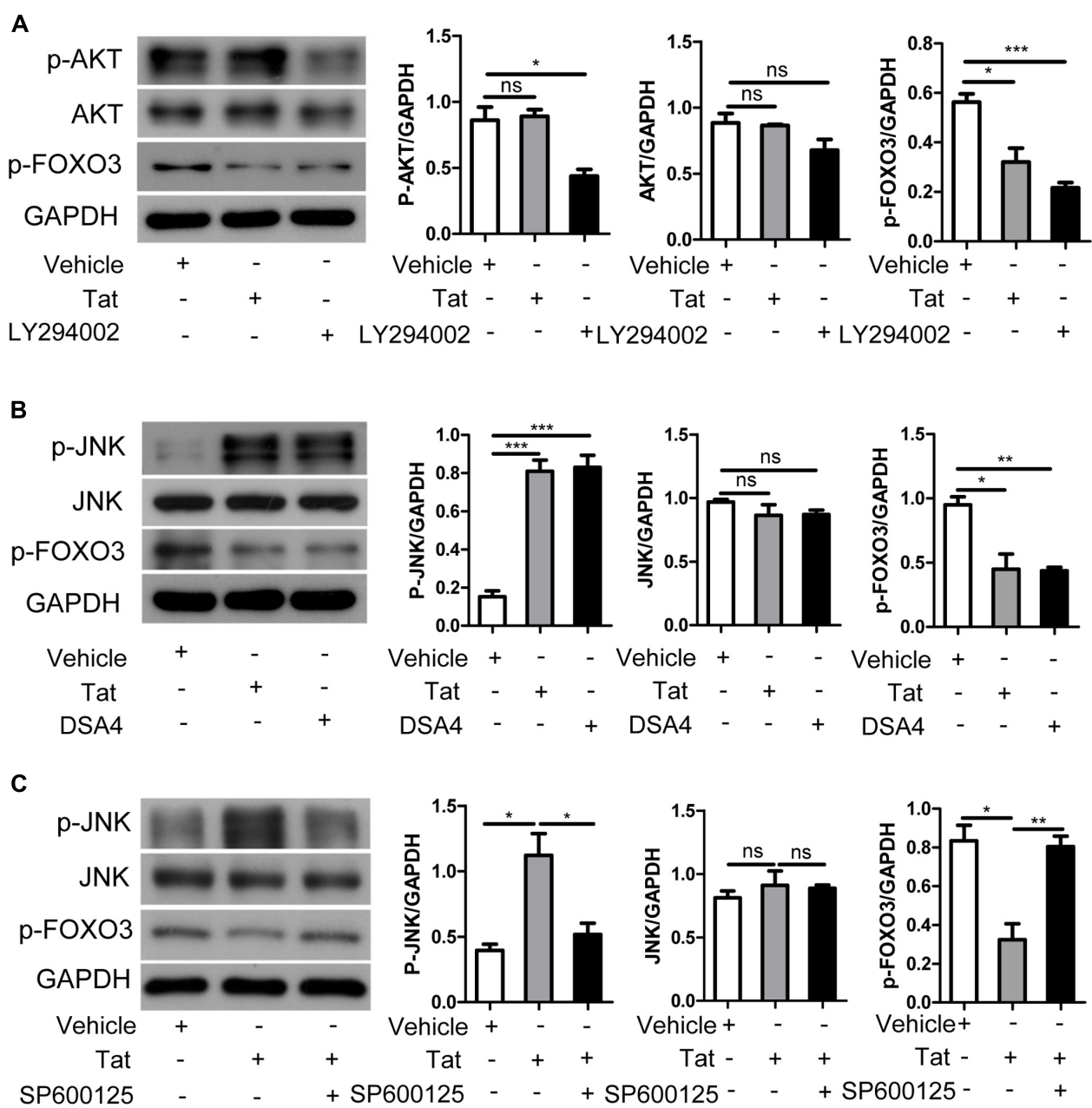

FIGURE 4 | HIV-1 Tat regulates FOXO3 via the JNK signaling pathway. (A) SH-SY5Y cells were transfected with pcDNA3.1-flag or pcDNA3.1-Tat-flag for 48 h or treated with PI3K-Akt inhibitor LY294002 (20 $\mu \mathrm{g} / \mathrm{mL})$. The expression of phosphorylated AKT, AKT and phosphorylated FOXO3 was analyzed by Western blotting. Statistical analysis is on the right $\left({ }^{*} P<0.05\right)$. (B) SH-SY5Y cells were transfected with pcDNA3.1-flag or pcDNA3.1-Tat-flag for $48 \mathrm{~h}$ or treated with JNK activator DSA4 (4 $\mu \mathrm{M})$. The expression of phosphorylated JNK, JNK and phosphorylated FOXO3 was analyzed by Western blotting. Statistical analysis is on the right $\left({ }^{*} P<0.05 ;{ }^{*} P<0.01 ;{ }^{* * *} P<0.001\right)$. (C) SH-SY5Y cells were transfected with pcDNA3.1-flag or pcDNA3.1-Tat-flag only for $48 \mathrm{~h}$, or were pre-treated with the JNK inhibitor SP600125 $(20 \mu \mathrm{M})$ followed transfection with pcDNA3.1-Tat-flag for $48 \mathrm{~h}$. The expression of phosphorylated JNK, JNK and phosphorylated FOXO3 was analyzed by Western blotting. Statistical analysis is on the right $\left({ }^{*} P<0.05 ;{ }^{* *} P<0.01\right)$. Statistical analyses of all Western blots were of at least three independent repeated experiments. Vehicle: pcDNA3.1-flag; Tat: pcDNA3.1-Tat-flag. 
cytoplasm to nucleus via the JNK signaling pathway in SH-SY5Y cells.

\section{Activated FOXO3 Induction of Apoptosis by Regulating Downstream Pro-apoptotic/Anti-apoptotic Genes Expression}

We next explored whether apoptosis-related gene expression and cellular apoptosis would be affected after the activation of FOXO3 induced by HIV-1 Tat. SH-SY5Y cells were transfected with pcDNA3.1-Tat-flag or pcDNA3.1-flag in order to active FOXO3, and expression of pro-apoptotic/anti-apoptotic genes was measured by qRT-PCR and Western blotting. At the transcriptional level, activated $\mathrm{FOXO} 3$ caused a significant increase in the transcription of pro-apoptotic genes Bim, Trail and P53, but no obvious change in Fas Ligand (FasL) transcription, and activated FOXO3 caused a distinct decrease in the transcriptional level of the anti-apoptotic genes BCL2 and MCL1 (Figure 5A). We then investigated whether the gene changes induced by activated FOXO3 at the transcriptional level were also altered at the protein level. As at the transcription levels, activated FOXO3 caused an increase in Bim protein expression and a decrease in Bcl-2 protein expression. However, we did not find any apparent changes in the protein level of Trail, P53, or Mcl-1 (Figure 5B).

To confirm the relationship between the activated FOXO3 induced by HIV-1 Tat and cellular apoptosis, SH-SY5Y cells were transfected with pcDNA3.1-Tat-flag or pcDNA3.1-flag for $48 \mathrm{~h}$ and then assessed by TUNEL assay. As shown in Figure 5C, activated FOXO3 caused a significant increase in TUNEL positivity. We also transfected the SH-SY5Y cells separately with the plasmids aforementioned for $48 \mathrm{~h}$ or treated them with STS (which caused cellular apoptosis) for $48 \mathrm{~h}$; we then analyzed caspase 3/7 activity. As shown in Figure 5D, activated FOXO3 gave rise to a remarkable increase in caspase $3 / 7$ activity. These data indicated that FOXO3 was activated by HIV-1 Tat and in turn selectively regulated the changes of its downstream pro-apoptotic and anti-apoptotic genes, eventually causing the apoptosis of SH-SY5Y cells.

\section{FOXO3 Plays a Key Role in Inducing Neuronal Apoptosis}

To further investigate the role of FOXO3 in cellular apoptosis, we transfected SH-SY5Y cells with only pcDNA3.1-Tat-flag or pcDNA3.1-flag, or transfected SH-SY5Y cells with scramblesiRNA or FOXO3-siRNA before pcDNA3.1-Tat-flag. Treatment with FOXO3-siRNA alone significantly reduced the expression of FOXO3 over that observed with transfection with scramblesiRNA (Figure 6A). In nuclear protein, knockdown of FOXO3 visibly reduced the increase in FOXO3 nucleoprotein caused by HIV-1 Tat (Figure 6B). Both the cytoplasmic FOXO3 and total $\mathrm{FOXO} 3$ were lower with knocking down FOXO3 before treatment with pcDNA3.1-Tat-flag than when treated with pcDNA3.1-Tat-flag and scramble-siRNA (Figures 6C,D). In addition, the increase in Bim and the decrease in Bcl-2 were not observed when FOXO3 was suppressed (Figure 6E). Similar issues were observed in the caspase 3/7 activity experiment (Figure 6F). These results indicated that $\mathrm{FOXO} 3$ was the key event required for apoptosis of SH-SY5Y cells.

\section{DISCUSSION}

Although neuronal apoptosis is a significant pathological characteristic of HAND (Adle-Biassette et al., 1995; Petito and Roberts, 1995), the mechanism remains unclear. Additionally, there have been reports that $\mathrm{FOXO} 3$ is associated with cellular apoptosis and that its active form may facilitate apoptosis of macrophages infected by HIV-1 (Calnan and Brunet, 2008; Cui et al., 2008). Nevertheless, the role of FOXO3 in HAND has not been fully addressed. Therefore, this study aimed to elucidate whether the transcriptional regulator protein $\mathrm{FOXO} 3$ regulates neuronal damage of HAND.

We first chose SHIV-infected rhesus macaques as animal models for research. The rhesus macaque is one of the most-frequently utilized animal models for HIV-associated pathogenesis research because it tends to develop AIDSlike diseases caused by primate lentivirus infection $(\mathrm{Hu}$, 2005; Lackner and Veazey, 2007; Polacino et al., 2008). SHIV is an infectious recombinant virus between HIV-1 and SIVmac239 (first isolated from rhesus macaques with AIDSlike diseases or lymphoma); it can establish sustained infection in rhesus macaques and generates symptoms similar to those induced by HIV-1 in humans, including lag in response and bradykinesia, which are the clinical features of HAND (Luciw et al., 1995; Lu et al., 1996; Vlasak and Ruprecht, 2006; Antinori et al., 2007; Polacino et al., 2008). Here, we chose the cerebral cortex of rhesus macaques for detection because this brain region is known to be home to many of the HIV-1-associated neurocognitive deficits in HAND patients (Lopez-Villegas et al., 1997). Moreover, satellitosis and neuronophagia were observed with HE staining in our research. Satellitosis and neuronophagia are phenomena that have been proven to occur in neurodegenerative diseases and the important pathological change of them are neuronal death (Troost et al., 1993; Sarnat and Flores-Sarnat, 2013), characteristics that are consistent with HAND. Furthermore, IHC revealed activation of astrocytes, characterized by diffuse astrocytic gliosis and increased cytoplasmic accumulation of the intermediate filament GFAP, in the cerebral cortexes of SHIV-infected rhesus macaques in our study, which is the histopathologic hallmark of HAND (Navia et al., 1986; Masliah et al., 1992; Fan and He, 2016). Thus, SHIV-infected rhesus macaques were considered a good animal model for studying HAND.

It has been reported that an increase in FOXO3 activity causes neurodegenerative diseases such as Alzheimer's and Parkinson's (Qin et al., 2008; Su et al., 2009). According to others previous research (Calnan and Brunet, 2008), FOXO3 may regulate the transcriptional expression of apoptosis-related genes and, thereby, regulate cellular apoptosis (Birkenkamp and Coffer, 2003), which is involved in the neuronal pathological changes of HAND. Furthermore, neurons are the most abundant cell type in 


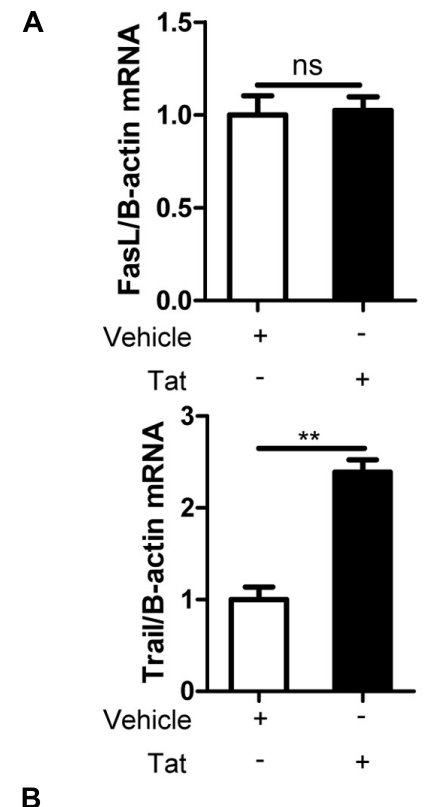

в

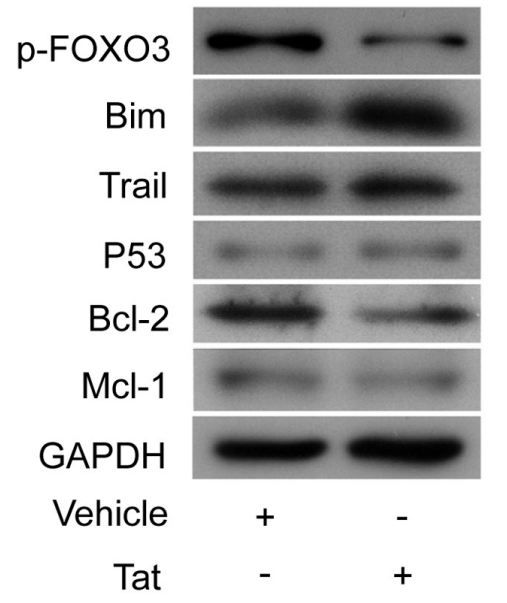

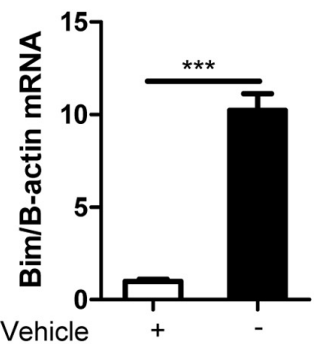

Vehicle

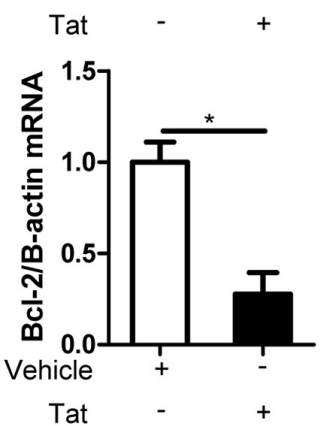

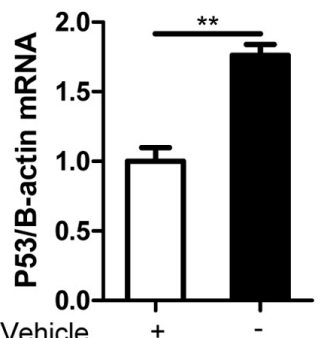

Vehicle

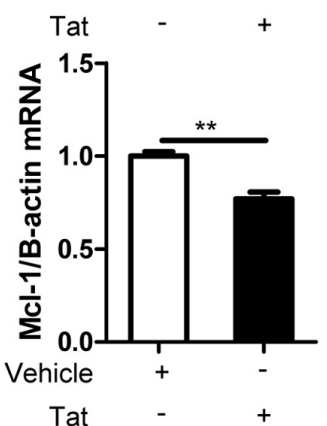

Tat

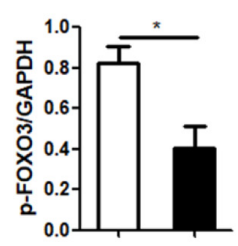

Vehicle + -

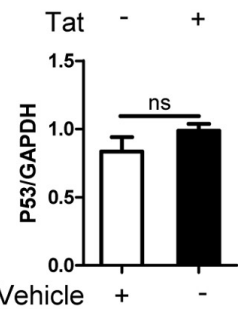

Vehicle +

Tat

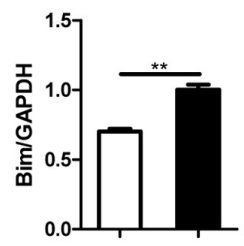

Vehicle +

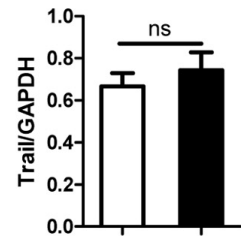

Vehicle

Vehicle
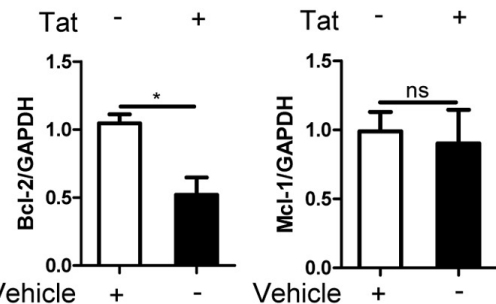

Tat - +
C

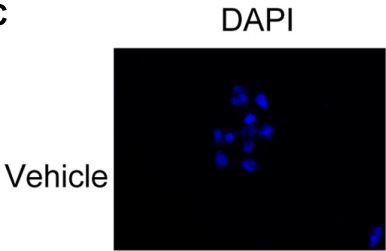

TUNEL
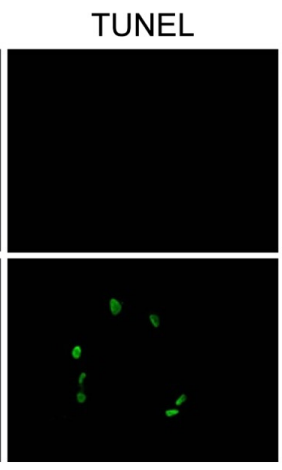
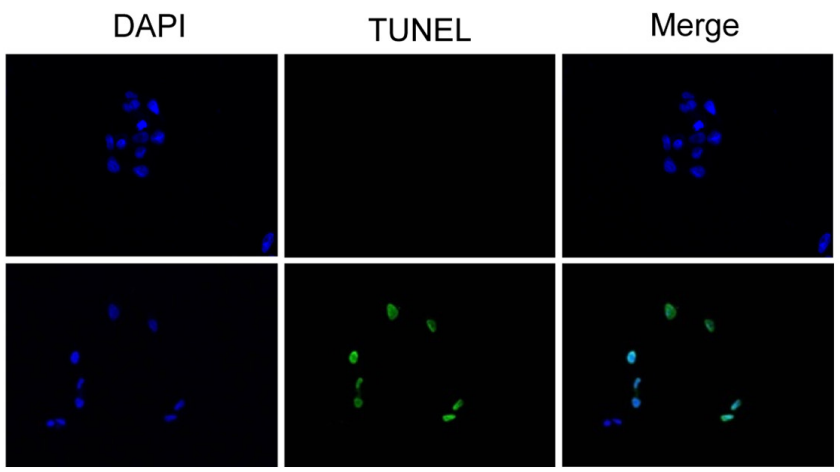

D

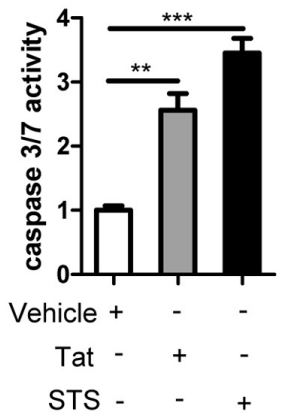

FIGURE 5 | Activated FOXO3 induces apoptosis by regulating downstream apoptosis-related genes. SH-SY5Y cells were transfected with pcDNA3.1-flag or pcDNA3.1-Tat-flag for 48 h. (A) Statistical analysis of the mRNA level of pro-apoptotic gene FasL, Bim, P53, Trail and anti-apoptotic gene Bcl-2, Mcl-1 measured by qRT-PCR. (B) The expression of Bim, Trail, P53, Bcl-2 and Mcl-1 was analyzed by Western blotting. Statistical analysis is on the right (* $P<0.05$; ** $P<0.01)$. (C) The apoptosis of SH-SY5Y cells was visualized with TUNEL staining and observed by confocal microscopy. Green indicates apoptosis cells and blue indicates cellular nuclei. Pictures were magnified $400 \times$. (D) The cells were transfected with plasmids or treated with STS (0.5 $\mu$ M) for 48 h. The apoptosis of SH-SY5Y cells was detected by measuring caspase $3 / 7$ activity, and the statistical analysis is presented $(* * P<0.01 ; * * * P<0.001)$. Statistical analyses of all Western blotting were of at least three independent repeated experiments. Vehicle: pcDNA3.1-flag; Tat: pcDNA3.1-Tat-flag. 
A

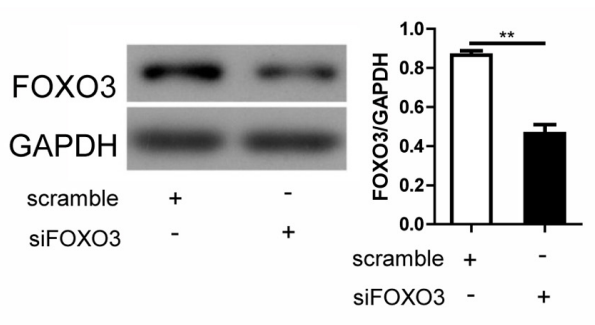

B

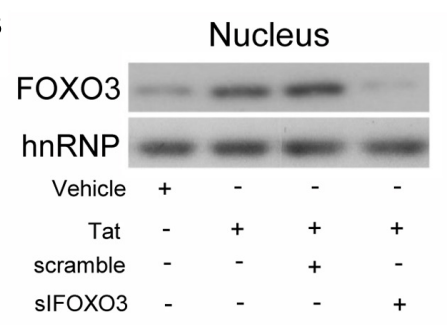

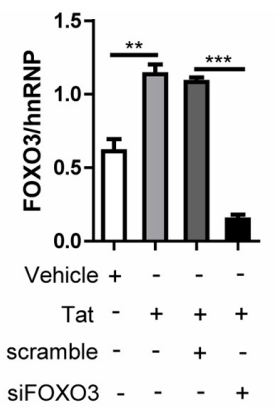

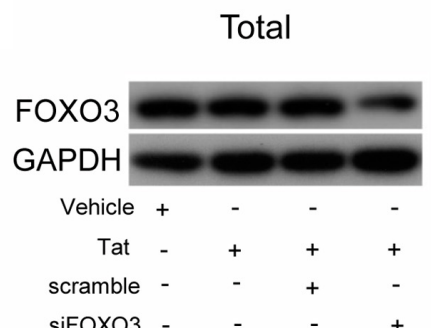

D

E

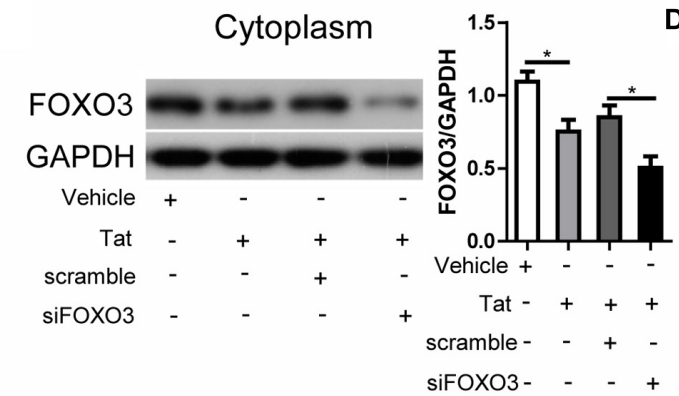

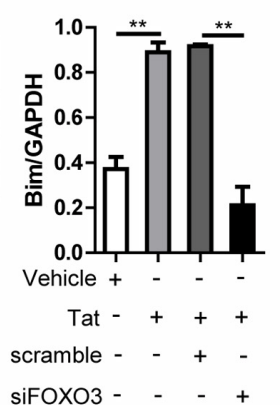

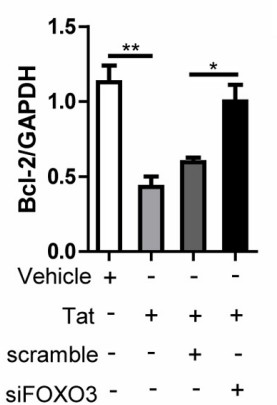

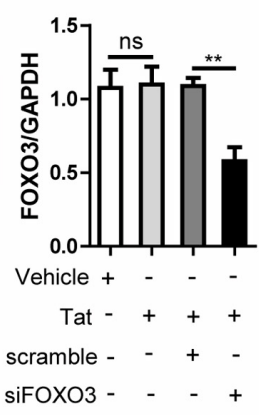

$\mathbf{F}$

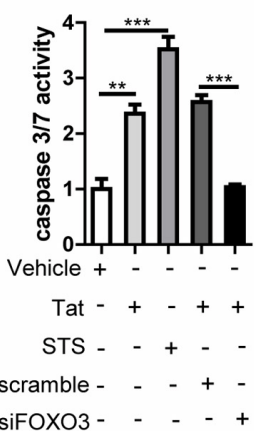

FIGURE 6 | FOXO3 plays a vital role in neuronal apoptosis. SH-SY5Y cells were transfected with pcDNA3.1-flag or pcDNA3.1-Tat-flag only for $48 \mathrm{~h}$, or were treated with scramble-siRNA or FOXO3-siRNA for $24 \mathrm{~h}$ followed by transfection with pcDNA3.1-Tat-flag for $48 \mathrm{~h}$. (A) Expression of FOXO3 was analyzed by Western blotting. Statistical analysis is on the right ( $\left.{ }^{* *} P<0.01\right)$. (B) Expression of nuclear FOXO3 was analyzed by Western blotting. Statistical analysis is on the right $\left({ }^{* *} P<0.01 ;{ }^{* * *} P<0.001\right)$. (C) Expression of cytoplasmic FOXO3 was analyzed by Western blotting. Statistical analysis is on the right $\left({ }^{*} P<0.05\right)$. (D) Expression of total FOXO3 was analyzed by Western blotting. Statistical analysis is on the right $(* * P<0.01)$. (E) Expression of Bim and Bcl-2 was analyzed by Western blotting. Statistical analysis is on the right (** $P<0.01)$. (F) Apoptosis of SH-SY5Y cells was detected by measuring caspase $3 / 7$ activity, and the statistical analysis is presented $\left.{ }^{* *} P<0.01 ;{ }^{* * *} P<0.001\right)$. Statistical analyses of all Western blots were of at least three independent repeated experiments. Vehicle: pcDNA3.1-flag; Tat: pcDNA3.1-Tat-flag. Scramble: scramble-siRNA. siFOXO3: FOXO3-siRNA.

the cerebral cortex; therefore, FOXO3's effects on neurons may have significant disease implications. We investigated whether the expression of $\mathrm{FOXO} 3$ had some changes in the neurons of SHIV-infected rhesus macaque cerebral cortexes. Our results showed that FOXO3 was widely expressed in the cerebral cortex and that the increase in nuclear FOXO3 may be associated with neuronal apoptosis in SHIV-infected rhesus macaques.

How is the expression of FOXO3 regulated in neurons? Recent studies have revealed that neurons are damaged despite the fact that HIV-1 does not directly infect them (Kaul et al., 2001). Some studies have indicated that several HIV-1-encoded proteins are primary causes of neuronal injury in HAND (Kaul et al., 2001). HIV-1 Tat, a potent neurotoxic viral protein (Nath et al., 1996; Chang et al., 2011) secreted by HIV-infected cells such as glial cells (Tardieu et al., 1992; Ensoli et al., 1993), is one of the most widely detected HIV-1-encoded proteins in the serum and cerebrospinal fluid of HIV-1-infected patients and is thought to be a crucial mediator of neurological dysfunction (Nath, 2002). Additionally, experiments performed in transgenic mice that specifically express HIV-1 Tat protein, have confirmed that transgenic mice without HIV-1 infection but expressing HIV-1 Tat exhibit similar recognition and behavioral changes as HAND patients (Kim et al., 2003). Furthermore, our former works have demonstrated that HIV-1 Tat may participate in the pathogenesis of HAND (Ye et al., 2017; Wu et al., 2018). Accordingly, we surmised that the expression of FOXO3 in neurons potentially regulated by HIV-1 Tat in HAND. We chose SH-SY5Y for the further cellular level exploration because it 
is a human-derived neuroblastoma cell line that is frequently used as a model for researching neurodegenerative disease such as Alzheimer's and Parkinson's (Krishna et al., 2014). Research has found that the transcriptional activity of FOXO3 is regulated by various mechanisms, including ubiquitination, acetylation, and phosphorylation (Calnan and Brunet, 2008). In some studies related to cellular apoptosis, expression or activation of FOXO3 favored the phosphorylated phenotype; researchers, also showed that inactivating phosphorylation of FOXO3 resulted in its export from the nucleus and inhibition of its transcription of pro-apoptotic genes (Brunet et al., 1999; Modur et al., 2002; You et al., 2006; Rosich et al., 2013). Interestingly, our results indicated that HIV-1 Tat could reduce the phosphorylation of FOXO3 and facilitate the dephosphorylation of FOXO3 in SH-SY5Y cells. Furthermore the nucleus and cytoplasm separation assay demonstrated that FOXO3 was dephosphorylated by HIV-1 Tat to be an activated status and then translocate from the cytoplasm to nucleus.

There are two primary mechanisms for regulation of FOXO3: phosphoinositide 3-kinase/AKT pathway and the JNK pathway (Huang and Tindall, 2007). AKT can phosphorylate $\mathrm{FOXO} 3$ and leads to $\mathrm{FOXO} 3$ sequestration in the cytoplasm (Brunet et al., 1999); conversely, JNK promotes dephosphorylating of $\mathrm{FOXO} 3$ and translocation into the nucleus ( $\mathrm{Li}$ et al., 2015). Therefore, we aimed to address whether these two pathways were involved in the regulation of FOXO3 induced by HIV-1 Tat in SH-SY5Y cells. Our results illustrated that HIV-1 Tat caused activation of JNK but had no effect on AKT. The role of JNK in the HIV-1 Tat-induced dephosphorylating of FOXO3 is further demonstrated by our finding that inhibiting JNK remitted the HIV-1 Tatinduced reducing in phosphorylated FOXO3. As a result, we concluded that HIV-1 Tat activated FOXO3 through the JNK signaling pathway rather than through the AKT signaling pathway.

In accordance with the departed survey, dephosphorylated FOXO3 translocated to the nucleus and became transcriptionally active to participate in regulating apoptosis, cell cycle, DNA repair and so on (Brunet et al., 1999; Calnan and Brunet, 2008; Tia et al., 2018). Results of the tissue experiments suggested that increased nuclear FOXO3 might be involved in the neuronal apoptotic process of HAND. FOXO3 may target downstream transcriptional pathways by activating or deactivating apoptosisrelated genes; the most-studied of these include the pro-apoptotic genes FasL, Bim, P53, and Trail, and the anti-apoptotic gene BCL2, MCL1 (Brunet et al., 1999; Modur et al., 2002; You et al., 2006; Rosich et al., 2013). Disequilibrium of Bim and Bcl-2 or Mcl-1 results in disruption of mitochondrial transmembrane potential, facilitating activation of caspases and eventually leading to cellular apoptosis (Schmidt et al., 2006; Krishna et al., 2011; Anilkumar and Prehn, 2014). FasL and Trail can bind to their receptors in turn causing caspase cascades and propagating the process of cellular apoptosis (Nagata, 1997; Vasaikar et al., 2015). The P53 protein regulates cellular apoptosis through multiple pathways, including activating the expression of proapoptotic genes and promoting the formation of apoptosome
(Wawryk-Gawda et al., 2014; Deng et al., 2017). To identify genes incorporated in our model, we utilized qRT-PCR to define that Bim, P53, Trial, Bcl-2 and Mcl-1-but not FasL- as novel targets regulated by nuclear FOXO3 at the transcriptional level. Although we uniformly observed that nuclear accessorial FOXO3 increased Bim and decreased Bcl-2 at the mRNA, as well as the protein levels, we were unable to find changes in P53, Trail, or Mcl-1 at the protein level; these results were inconsistent with their mRNA levels. Using the TUNEL assay and analysing the activity of caspase $3 / 7$, our results proved that activated FOXO3 induced by HIV-1 Tat triggered the apoptosis of SH-SY5Y cells by regulating the expression Bim and Bcl-2. To further confirm the role of $\mathrm{FOXO} 3$ in neuronal apoptosis, we found that when the FOXO3 was knocked down, FOXO3 entering the nucleus was consequently reduced. Meanwhile, silencing FOXO3 restored the expression of Bim and Bcl-2, and altered the SH-SY5Y cellular apoptosis. On the basis of these results we concluded that FOXO3 had a vital effect on the apoptosis of SH-SY5Y cells.

In summary, our work reveals for the first time that FOXO3 can be activated by HIV-1 Tat via the JNK signaling pathway and then promotes neuronal apoptosis by means of direct transcriptional repression of Bcl-2 and activation of Bim. We considered that FOXO3-dependent neural apoptosis may play a role in the pathogenesis of HAND. Hence, we provide here a further understanding of the HAND pathogenesis mechanism and the FOXO3 may be the potential promising target for the therapy of HAND.

\section{AUTHOR CONTRIBUTIONS}

HX instructed all investigations. HD designed and performed the experiments, collected and analyzed the data, and wrote and edited the manuscript. XY designed the research and reviewed the manuscript. LZ revised the manuscript. JX, JQ, and JW prepared the materials. YS provided SHIV-infected rhesus macaque specimens.

\section{FUNDING}

This project was supported by the National Science Research Foundation of China (Grant No. 81271895), the Natural Science Foundation of Fujian Province of China (Grant No. 2018J01134), Start-up Research Fund (Grant Nos. ZK1011 and ZK1014), and the Science Foundation Introduction of Talented Person from Xiamen University (Grant No. 0000X09401).

\section{ACKNOWLEDGMENTS}

We are grateful to Prof. Zhou Q. from the Department of Molecular and Cell Biology, University of California, Berkeley, United States, and Xue Y. from the School of Pharmaceutical Sciences, Xiamen University, Xiamen, China. 


\section{REFERENCES}

Adle-Biassette, H., Levy, Y., Colombel, M., Poron, F., Natchev, S., Keohane, C., et al. (1995). Neuronal apoptosis in HIV infection in adults. Neuropathol. Appl. Neurobiol. 21, 218-227. doi: 10.1111/j.1365-2990.1995.tb0 1053.x

Anilkumar, U., and Prehn, J. H. (2014). Anti-apoptotic BCL-2 family proteins in acute neural injury. Front. Cell. Neurosci. 8:281. doi: 10.3389/fncel.2014.00281

Antinori, A., Arendt, G., Becker, J. T., Brew, B. J., Byrd, D. A., Cherner, M., et al. (2007). Updated research nosology for HIV-associated neurocognitive disorders. Neurology 69, 1789-1799. doi: 10.1212/01.WNL.0000287431.88 $658.8 \mathrm{~b}$

Birkenkamp, K. U., and Coffer, P. J. (2003). Regulation of cell survival and proliferation by the FOXO (Forkhead box, class O) subfamily of Forkhead transcription factors. Biochem. Soc. Trans. 31, 292-297. doi: 10.1042/bst03 10292

Brunet, A., Bonni, A., Zigmond, M. J., Lin, M. Z., Juo, P., Hu, L. S., et al. (1999). Akt promotes cell survival by phosphorylating and inhibiting a Forkhead transcription factor. Cell 96, 857-868. doi: 10.1016/S0092-8674(00)80595-4

Cadet, J. L., and Krasnova, I. N. (2007). Interactions of HIV and methamphetamine: cellular and molecular mechanisms of toxicity potentiation. Neurotox. Res. 12, 181-204. doi: 10.1007/BF03033915

Calnan, D. R., and Brunet, A. (2008). The FoxO code. Oncogene 27, 2276-2288. doi: 10.1038/onc.2008.21

Chang, J. R., Mukerjee, R., Bagashev, A., Del Valle, L., Chabrashvili, T., Hawkins, B. J., et al. (2011). HIV-1 Tat protein promotes neuronal dysfunction through disruption of microRNAs. J. Biol. Chem. 286, 41125-41134. doi: 10.1074/jbc. M111.268466

Cui, M., Huang, Y., Zhao, Y., and Zheng, J. (2008). Transcription factor FOXO3a mediates apoptosis in HIV-1-infected macrophages. J. Immunol. 180, 898-906. doi: 10.4049/jimmunol.180.2.898

Deng, X., Song, L., Zhao, W., Wei, Y., and Guo, X. B. (2017). HAX-1 protects glioblastoma cells from apoptosis through the Akt1 pathway. Front. Cell. Neurosci. 11:420. doi: 10.3389/fncel.2017.00420

Dijkers, P. F., Medema, R. H., Pals, C., Banerji, L., Thomas, N. S., Lam, E. W., et al. (2000). Forkhead transcription factor FKHR-L1 modulates cytokine-dependent transcriptional regulation of p27(KIP1). Mol. Cell. Biol. 20, 9138-9148. doi: 10.1128/MCB.20.24.9138-9148.2000

Ensoli, B., Buonaguro, L., Barillari, G., Fiorelli, V., Gendelman, R., Morgan, R. A., et al. (1993). Release, uptake, and effects of extracellular human immunodeficiency virus type 1 Tat protein on cell growth and viral transactivation. J. Virol. 67, 277-287.

Fan, Y., and He, J. J. (2016). HIV-1 tat induces unfolded protein response and endoplasmic reticulum stress in astrocytes and causes neurotoxicity through Glial Fibrillary Acidic Protein (GFAP) activation and aggregation. J. Biol. Chem. 291, 22819-22829. doi: 10.1074/jbc.M116.731828

Fox, L., Alford, M., Achim, C., Mallory, M., and Masliah, E. (1997). Neurodegeneration of somatostatin-immunoreactive neurons in HIV encephalitis. J. Neuropathol. Exp. Neurol. 56, 360-368. doi: 10.1097/00005072199704000-00004

Greer, E. L., and Brunet, A. (2005). FOXO transcription factors at the interface between longevity and tumor suppression. Oncogene 24, 7410-7425. doi: 10. 1038/sj.onc. 1209086

Hu, S. L. (2005). Non-human primate models for AIDS vaccine research. Curr. Drug Targets Infect. Disord. 5, 193-201. doi: 10.2174/1568005054201508

Huang, H., and Tindall, D. J. (2007). Dynamic FoxO transcription factors. J. Cell Sci. 120(Pt 15), 2479-2487. doi: 10.1242/jcs.001222

Kaul, M., Garden, G. A., and Lipton, S. A. (2001). Pathways to neuronal injury and apoptosis in HIV-associated dementia. Nature 410, 988-994. doi: 10.1038/ 35073667

Kim, B. O., Liu, Y., Ruan, Y., Xu, Z. C., Schantz, L., and He, J. J. (2003). Neuropathologies in transgenic mice expressing human immunodeficiency virus type 1 Tat protein under the regulation of the astrocyte-specific glial fibrillary acidic protein promoter and doxycycline. Am. J. Pathol. 162, 1693-1707. doi: 10.1016/s0002-9440(10)64304-0

Krishna, A., Biryukov, M., Trefois, C., Antony, P. M., Hussong, R., Lin, J., et al. (2014). Systems genomics evaluation of the SH-SY5Y neuroblastoma cell line as a model for Parkinson's disease. BMC Genomics 15:1154 doi: 10.1186/14712164-15-1154

Krishna, S., Low, I. C., and Pervaiz, S. (2011). Regulation of mitochondrial metabolism: yet another facet in the biology of the oncoprotein Bcl-2. Biochem. J. 435, 545-551. doi: 10.1042/BJ20101996

Lackner, A. A., and Veazey, R. S. (2007). Current concepts in AIDS pathogenesis: insights from the SIV/macaque model. Annu. Rev. Med. 58, 461-476. doi: 10.1146/annurev.med.58.082405.094316

Li, D., Li, X., Wu, J., Li, J., Zhang, L., Xiong, T., et al. (2015). Involvement of the JNK/FOXO3a/Bim pathway in neuronal apoptosis after hypoxic-ischemic brain damage in neonatal rats. PLoS One 10:e132998. doi: 10.1371/journal. pone.0132998

Lopez-Villegas, D., Lenkinski, R. E., and Frank, I. (1997). Biochemical changes in the frontal lobe of HIV-infected individuals detected by magnetic resonance spectroscopy. Proc. Natl. Acad. Sci. U.S.A. 94, 9854-9859. doi: 10.1073/pnas.94. 18.9854

Lu, Y., Brosio, P., Lafaile, M., Li, J., Collman, R. G., Sodroski, J., et al. (1996). Vaginal transmission of chimeric simian/human immunodeficiency viruses in rhesus macaques. J. Virol. 70, 3045-3050.

Luciw, P. A., Pratt-Lowe, E., Shaw, K. E., Levy, J. A., and Cheng-Mayer, C. (1995). Persistent infection of rhesus macaques with T-cell-line-tropic and macrophage-tropic clones of simian/human immunodeficiency viruses (SHIV). Proc. Natl. Acad. Sci. U.S.A. 92, 7490-7494. doi: 10.1073/pnas.92.16.7490

Maragos, W. F., Tillman, P., Jones, M., Bruce-Keller, A. J., Roth, S., Bell, J. E., et al. (2003). Neuronal injury in hippocampus with human immunodeficiency virus transactivating protein, Tat. Neuroscience 117, 43-53. doi: 10.1016/s03064522(02)00713-3

Masliah, E., Achim, C. L., Ge, N., DeTeresa, R., Terry, R. D., and Wiley, C. A. (1992). Spectrum of human immunodeficiency virus-associated neocortical damage. Ann. Neurol. 32, 321-329. doi: 10.1002/ana.410320304

McArthur, J. C., Steiner, J., Sacktor, N., and Nath, A. (2010). HIV-associated neurocognitive disorders: 'mind the gap'. Ann. Neurol. 67, 699-714. doi: 10. 1002/ana.22053

Modur, V., Nagarajan, R., Evers, B. M., and Milbrandt, J. (2002). FOXO proteins regulate tumor necrosis factor-related apoptosis inducing ligand expression. Implications for PTEN mutation in prostate cancer. J. Biol. Chem. 277, 47928-47937. doi: 10.1074/jbc.M207509200

Nagata, S. (1997). Apoptosis by death factor. Cell 88, 355-365. doi: 10.1016/S00928674(00)81874-7

Nath, A. (2002). Human immunodeficiency virus (HIV) proteins in neuropathogenesis of HIV dementia. J. Infect. Dis. 186(Suppl. 2), S193-S198. doi: $10.1086 / 344528$

Nath, A., Psooy, K., Martin, C., Knudsen, B., Magnuson, D. S., Haughey, N., et al. (1996). Identification of a human immunodeficiency virus type 1 Tat epitope that is neuroexcitatory and neurotoxic. J. Virol. 70, 1475-1480.

Navia, B. A., Cho, E. S., Petito, C. K., and Price, R. W. (1986). The AIDS dementia complex: II. Neuropathology. Ann. Neurol. 19, 525-535. doi: 10.1002/ana. 410190603

New, D. R., Ma, M., Epstein, L. G., Nath, A., and Gelbard, H. A. (1997). Human immunodeficiency virus type 1 Tat protein induces death by apoptosis in primary human neuron cultures. J. Neurovirol. 3, 168-173. doi: 10.3109/ 13550289709015806

Petito, C. K., and Roberts, B. (1995). Evidence of apoptotic cell death in HIV encephalitis. Am. J. Pathol. 146, 1121-1130.

Polacino, P., Larsen, K., Galmin, L., Suschak, J., Kraft, Z., Stamatatos, L., et al. (2008). Differential pathogenicity of SHIV infection in pig-tailed and rhesus macaques. J. Med. Primatol. 37(Suppl. 2), 13-23. doi: 10.1111/j.1600-0684.2008. 00325.x

Qin, W., Zhao, W., Ho, L., Wang, J., Walsh, K., Gandy, S., et al. (2008). Regulation of forkhead transcription factor FoxO3a contributes to calorie restrictioninduced prevention of Alzheimer's disease-type amyloid neuropathology and spatial memory deterioration. Ann. N. Y. Acad. Sci. 1147, 335-347. doi: 10.1196/ annals. 1427.024

Rosich, L., Saborit-Villarroya, I., Lopez-Guerra, M., Xargay-Torrent, S. Montraveta, A., Aymerich, M., et al. (2013). The phosphatidylinositol3-kinase inhibitor NVP-BKM120 overcomes resistance signals derived from microenvironment by regulating the Akt/FoxO3a/Bim axis in 
chronic lymphocytic leukemia cells. Haematologica 98, 1739-1747. doi: 10.3324/haematol.2013.088849

Sarnat, H. B., and Flores-Sarnat, L. (2013). "Chapter 44 - neuropathology of pediatric epilepsy," in Handbook of Clinical Neurology, eds O. Dulac, M. Lassonde, and H. B. Sarnat (New York, NY: Elsevier), 399-416.

Schmidt, S., Rainer, J., Riml, S., Ploner, C., Jesacher, S., Achmuller, C., et al. (2006). Identification of glucocorticoid-response genes in children with acute lymphoblastic leukemia. Blood 107, 2061-2069. doi: 10.1182/blood-2005-072853

Su, B., Liu, H., Wang, X., Chen, S. G., Siedlak, S. L., Kondo, E., et al. (2009). Ectopic localization of FOXO3a protein in Lewy bodies in Lewy body dementia and Parkinson's disease. Mol. Neurodegener. 4:32. doi: 10.1186/1750-1326-4-32

Tan, R. C., Harouse, J. M., Gettie, A., and Cheng-Mayer, C. (1999). In vivo adaptation of SHIV(SF162): chimeric virus expressing a NSI, CCR5-specific envelope protein. J. Med. Primatol. 28, 164-168. doi: 10.1111/j.1600-0684.1999. tb00265.x

Tardieu, M., Hery, C., Peudenier, S., Boespflug, O., and Montagnier, L. (1992). Human immunodeficiency virus type 1-infected monocytic cells can destroy human neural cells after cell-to-cell adhesion. Ann. Neurol. 32, 11-17. doi: 10.1002/ana.410320104

Tia, N., Singh, A. K., Pandey, P., Azad, C. S., Chaudhary, P., and Gambhir, I. S. (2018). Role of Forkhead Box O (FOXO) transcription factor in aging and diseases. Gene 648, 97-105. doi: 10.1016/j.gene.2018.01.051

Tran, H., Brunet, A., Grenier, J. M., Datta, S. R., Fornace, A. J. Jr., DiStefano, P. S., et al. (2002). DNA repair pathway stimulated by the forkhead transcription factor FOXO3a through the Gadd45 protein. Science 296, 530-534. doi: 10. 1126/science. 1068712

Troost, D., Claessen, N., van den Oord, J. J., Swaab, D. F., and de Jong, J. M. (1993). Neuronophagia in the motor cortex in amyotrophic lateral sclerosis. Neuropathol. Appl. Neurobiol. 19, 390-397. doi: 10.1111/j.1365-2990.1993. tb00459.x

Vasaikar, S. V., Ghosh, S., Narain, P., Basu, A., and Gomes, J. (2015). HSP70 mediates survival in apoptotic cells-Boolean network prediction and experimental validation. Front. Cell. Neurosci. 9:319. doi: 10.3389/fncel.2015. 00319

Vlasak, J., and Ruprecht, R. M. (2006). AIDS vaccine development and challenge viruses: getting real. Aids 20, 2135-2140. doi: 10.1097/QAD.0b013e3280 10beb5

Wawryk-Gawda, E., Chylinska-Wrzos, P., Lis-Sochocka, M., Chlapek, K., Bulak, K., Jedrych, M., et al. (2014). P53 protein in proliferation, repair and apoptosis of cells. Protoplasma 251, 525-533. doi: 10.1007/s00709-013-05481
Wu, X., Dong, H., Ye, X., Zhong, L., Cao, T., Xu, Q., et al. (2018). HIV-1 Tat increases BAG3 via NF-kappaB signaling to induce autophagy during HIVassociated neurocognitive disorder. Cell Cycle 17, 1614-1623. doi: 10.1080/ 15384101.2018.1480219

Xing, H. Q., Hayakawa, H., Izumo, K., Kubota, R., Gelpi, E., Budka, H., et al. (2009a). In vivo expression of proinflammatory cytokines in HIV encephalitis: an analysis of 11 autopsy cases. Neuropathology 29, 433-442. doi: 10.1111/j. 1440-1789.2008.00996.x

Xing, H. Q., Moritoyo, T., Mori, K., Sugimoto, C., Ono, F., and Izumo, S. (2009b). Expression of proinflammatory cytokines and its relationship with virus infection in the brain of macaques inoculated with macrophage-tropic simian immunodeficiency virus. Neuropathology 29, 13-19. doi: 10.1111/j. 1440-1789.2008.00929.x

Xing, H. Q., Mori, K., Sugimoto, C., Ono, F., Izumo, K., Kuboda, R., et al. (2008). Impaired astrocytes and diffuse activation of microglia in the cerebral cortex in simian immunodeficiency virus-infected Macaques without simian immunodeficiency virus encephalitis. J. Neuropathol. Exp. Neurol. 67, 600-611. doi: 10.1097/NEN.0b013e3181772ce0

Xing, H. Q., Moritoyo, T., Mori, K., Tadakuma, K., Sugimoto, C., Ono, F., et al. (2003). Simian immunodeficiency virus encephalitis in the white matter and degeneration of the cerebral cortex occur independently in simian immunodeficiency virus-infected monkey. J. Neurovirol. 9, 508-518. doi: 10. 1080/13550280390218904

Ye, X., Zhang, Y., Xu, Q., Zheng, H., Wu, X., Qiu, J., et al. (2017). HIV-1 Tat inhibits EAAT-2 through AEG-1 upregulation in models of HIV-associated neurocognitive disorder. Oncotarget 8, 39922-39934. doi: 10.18632/oncotarget. 16485

You, H., Yamamoto, K., and Mak, T. W. (2006). Regulation of transactivationindependent proapoptotic activity of p53 by FOXO3a. Proc. Natl. Acad. Sci. U.S.A. 103, 9051-9056. doi: 10.1073/pnas.0600889103

Conflict of Interest Statement: The authors declare that the research was conducted in the absence of any commercial or financial relationships that could be construed as a potential conflict of interest.

Copyright (c) 2019 Dong, Ye, Zhong, Xu, Qiu, Wang, Shao and Xing. This is an open-access article distributed under the terms of the Creative Commons Attribution License (CC BY). The use, distribution or reproduction in other forums is permitted, provided the original author(s) and the copyright owner(s) are credited and that the original publication in this journal is cited, in accordance with accepted academic practice. No use, distribution or reproduction is permitted which does not comply with these terms. 